\title{
INTERPOLATING BETWEEN THE ARITHMETIC-GEOMETRIC MEAN AND CAUCHY-SCHWARZ MATRIX NORM INEQUALITIES
}

\author{
KoenraAd M. R. Audenaert
}

Abstract. We prove an inequality for unitarily invariant norms that interpolates between the Arithmetic-Geometric Mean inequality and the Cauchy-Schwarz inequality.

Mathematics subject classification (2010): 15A60.

Keywords and phrases: Eigenvalue inequality, matrix norm inequality.

\section{REFERENCES}

[1] T. Ando, Matrix Young inequalities, Operator Theory: Advances and Applications, 75 (1), 33-38, (1995).

[2] R. Bhatia, Perturbation inequalities for the absolute value map in norm ideals of operators, Journal of Operator Theory, 19 (1), 129-136, (1988).

[3] R. Bhatia, Matrix Analysis, Springer, Heidelberg, (1997).

[4] R. Bhatia AND F. KitTAneh, On the singular values of a product of operators, SIAM J. Matrix Analysis, 11 (2), 272-277, (1990).

[5] S. W. DruRY, On a question of Bhatia and Kittaneh, Linear Algebra Appl., 437 (7), 1955-1960, (2012).

[6] R. Horn AND R. Matthias, Cauchy-Schwarz inequalities associated with positive semidefinite matrices, Linear Algebra Appl., 142 (1), 63-82, (1990). 